\title{
PEPPER: A HUMANOID ROBOT WITH PERSONALITY?
}

\author{
Josef Guggemos, Sabine Seufert and Stefan Sonderegger \\ University of St.Gallen, St. Jakob-Str. 21, 9000 St. Gallen, Switzerland
}

\begin{abstract}
Perceived personality plays an important role in human-robot interaction. This paper uses the Big Five Inventory-2 (BFI-2-S) to assess the perceived personality of a type Pepper social robot. Pepper provided a sample of its capabilities during an introduction to academic writing university course. $\mathrm{N}=462$ students evaluated Pepper's personality by answering the BFI-2-S questions. A confirmatory factor analysis with the implied five-factor structure did not converge. A subsequent exploratory factor analysis yielded inconclusive results. Although we were not able to provide evidence for a Big Five personality structure of the social robot, perceived personality may be an important characteristic of a social robot: The latent correlation of a factor labeled 'positive characteristics' with the intention to use the robot equals .487.
\end{abstract}

\section{KEYWORDS}

Big Five, Personality, Social Robot, Pepper

\section{INTRODUCTION}

Social robots have the potential to become an integral part of the educational infrastructure (Belpaeme et al., 2018; Mubin et al., 2013): As tutors or teachers, robots might take over selected duties that human teachers carry out. By assisting the teacher, they free up resources. For instance, the robot can answer frequently asked questions, which allows the teacher to focus on other activities. As peers, social robots are companions of students and collaboratively learn with them. For example, they can act as time guards during group work and take the minutes. The aim of social robots is to communicate and interact with humans; most of them are designed to resemble humans to a certain degree (humanoid robots). Nao (see Figure 1), developed by SoftBank Robotics, may be a quasi-standard form in education (Belpaeme et al., 2018). In commercial settings, Pepper (see Figure 1), also a humanoid robot from SoftBank Robotics, is more widely used (Gardecki \& Podpora, 2017).

Perceived personality plays an important role in human-robot interaction (Lee et al., 2008). It may depend on visual appearance, language, vocal features, eye contact, and movement (Mou, Shi, Shen, \& Xu, 2020). Since these characteristics substantially vary among available social robots, this paper addresses the research question: Do students attribute a personality to a type Pepper social robot?

\section{THEORETICAL PERSPECTIVE}

\subsection{State of the Art}

Mou et al. (2020) reviewed the literature on personality of social robots. A definition or conceptualization of personality is often missing in the analyzed 40 studies. Personality is mostly captured with the psychoticism, extraversion and neuroticism (PEN) model or a Big Five inventory. The Big Five are an established concept for capturing the personality of humans; the five factors are usually labeled: Extraversion, Agreeableness, Conscientiousness, Neuroticism, and Openness (Goldberg, 1990). According to Mou et al. (2020), only one study has addressed the perceived personality of a type Pepper model: Craenen et al. (2018) used a Big Five inventory. The aim of this experimental study with 30 participants was to investigate the association between Pepper's gestures and the attributed personality. However, the authors did not present evidence for the quality of the personality measurement, i.e., if the Big Five can be captured in a valid and reliable manner. 


\subsection{The Present Study}

The study at hand is in the realm of social robots in higher education (Guggemos, Seufert, \& Sonderegger, 2020; Guggemos et al., 2020). It was carried out during a large-scale university course, 'Introduction to academic writing', which was mandatory for all the 1,552 freshmen at the University of St.Gallen. We drew on the work of Cooney and Leister (2019), who provided a list of tasks that social robots could carry out in higher education. Based on this, we developed samples that may fairly represent the capabilities of the social robot. Besides generic activities like greeting, we relied on our own experience regarding typical issues and questions in academic writing, e.g., how plagiarism is detected. A video that shows the performance of the robot can be found here: https://unisg.link/lexi2020. Overall, Lexi (name of the robot) supported the lecturer for about 45 minutes. We invited all students via the learning management system to fill in an online questionnaire. Students were asked to assess Lexi's personality by means of the short version of the Big Five Inventory-2 (BFI-2-S) that comprises 30 questions (Soto \& John, 2017). The questions can be found in Table 1. $N=462$ students (163 female) took part in our study. Their intended study subject was Business administration $(n=225)$, Economics $(n=102)$, International affairs $(n=71)$, Law $(n=28)$, and Law and economics $(n=36)$. On average, they were aged 19.78 years $(S D=1.42$ years). Missing values did not occur.
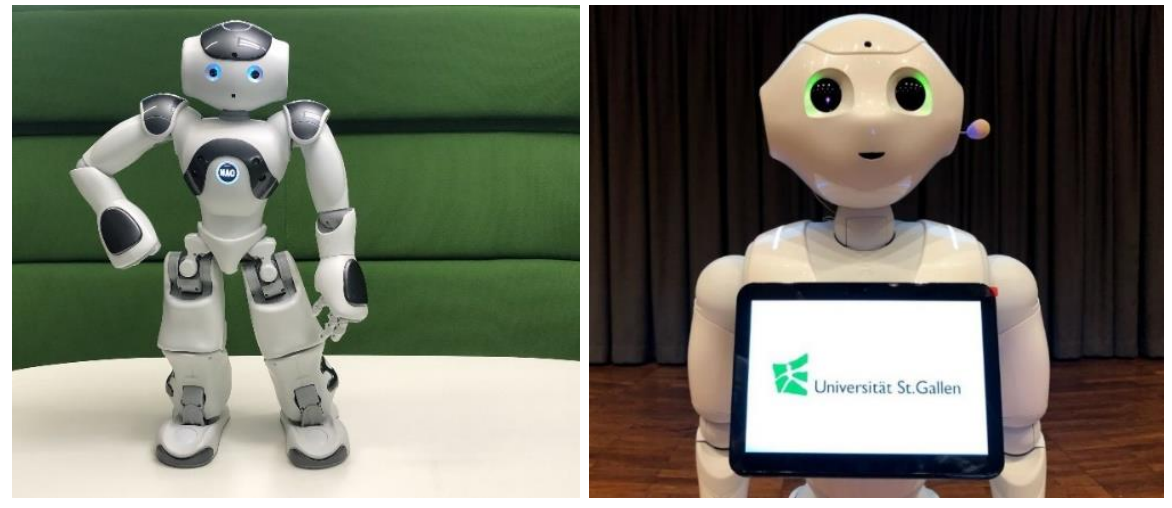

Figure 1. On the left, social robot 'Nao'; on the right, 'Pepper'

\subsection{Analysis}

Since (for human beings) there is strong evidence for a five-factor structure of personality, we first carried out a confirmatory factor analysis (CFA: R package 'lavaan' version 0.6-3). Each dimension is measured with six items on a five-point scale of rating (see Table 1). The CFA did not converge. Hence, we subsequently conducted an exploratory factor analysis (EFA: R package 'psych' version 1.8.12) and followed the guidelines of Goretzko, Pham, and Bühner (2019). The data showed slight deviations from a normal distribution. Thus, we used weighted least squares (WLS) as factoring method. Moreover, we applied a 'varimax' rotation (Soto \& John, 2017). Afterward, we evaluated if the extracted factors show a sufficient internal consistency reliability. To this end, we used Revell's $\omega$ because it is superior to Cronbach's alpha $\alpha$ (McNeish, 2018). An $\omega$ greater than .7 may point to sufficient reliability. However, since Cronbach's alpha $\alpha$ is widely used, we report it along with $\omega$.

The value and usefulness of the obtained factors should be judged by assessing the relationship with external criteria (Watkins, 2018). Against this backdrop, we correlated meaningful extracted constructs with the intention to use the robot for learning purposes, which is measured with three items, e.g., "I would rely on social robots like Lexi for learning purposes if they were available" $(\alpha=\omega=.92)$.

\section{RESULTS}

The CFA with the five-factor structure implied by theory did not converge. Moreover, the reliability of the five factors are in most cases insufficient. Extraversion: $\alpha=.52, \omega=.58$, Agreeableness: $\alpha=.41, \omega=.63$, Conscientiousness: $\alpha=.52, \omega=.66$, Neuroticism: $\alpha=.62, \omega=.77$, and Openness: $\alpha=.45, \omega=.71$. In terms 
of the EFA, the Kaiser-Meyer-Olkin criterion equals $.87(>.50)$ and the Bartlett test was significant $\left(\mathrm{Chi}^{2}=4,194, \mathrm{df}=435, \mathrm{p}<.001\right)$, which indicated the suitability of the data for EFA. We decided to extract three factors from the data because a parallel as well as a comparison data analysis revealed a three-factor structure as optimal. The results of the EFA can be found in Table 1. Based on this, we formed constructs using all items with a salient standardized loading on one factor $(\lambda>.5)$ that at the same time do not load substantially on a second factor $(\lambda<.3$ ) (Watkins, 2018). Following this rule, the first construct operationalized by the items E3, A3, C3, O3, and E4 (see Table 1) shows sufficient reliability: $\alpha=.75$, $\omega=.76$. The second construct comprising the items N1, E2, N2 and N6 lacks reliability $(\alpha=.62$, $\omega=.62)$. This is also true for the third factor with the items A4, C6, and O6 ( $\alpha=.64, \omega=.64)$. The latent correlation between the intention to use the robot for learning purposes and the first (only reliably measured) construct equals $.487(\mathrm{p}<.001)$.

Table 1. Exploratory factor analysis for personality of social robot $(\mathrm{N}=462)$

\begin{tabular}{|c|c|c|c|c|c|c|c|c|c|}
\hline \multirow[b]{2}{*}{ Item } & \multirow[b]{2}{*}{ Lexi ... } & \multicolumn{4}{|c|}{ Descriptive statistics } & \multicolumn{3}{|c|}{ Factor } & \multirow[b]{2}{*}{$\mathrm{h}^{2}$} \\
\hline & & Mean & SD & Skew & Kurt. & F1 & $\mathrm{F} 2$ & F3 & \\
\hline E1 & "tends to be quiet." (r) & 2.93 & 0.87 & -0.08 & -0.17 & -0.13 & -0.07 & 0.31 & 0.12 \\
\hline A1 & "compassionate, has a soft heart." & 2.84 & 0.97 & -0.34 & -0.44 & 0.45 & 0.31 & 0.14 & 0.32 \\
\hline $\mathrm{C} 1$ & "tends to be disorganized." (r) & 2.39 & 0.96 & 0.26 & -0.38 & 0.14 & -0.53 & 0.16 & 0.32 \\
\hline N1 & "worries a lot." & 2.49 & 0.88 & -0.21 & -0.31 & 0.07 & 0.62 & -0.05 & 0.39 \\
\hline $\mathrm{O} 1$ & "is fascinated by art, music, or literature." & 2.76 & 0.93 & -0.41 & 0.16 & 0.35 & 0.43 & 0.15 & 0.33 \\
\hline E2 & "is dominant, acts as a leader." & 2.50 & 1.02 & 0.10 & -0.58 & 0.17 & $\mathbf{0 . 5 0}$ & 0.09 & 0.29 \\
\hline $\mathrm{A} 2$ & "is sometimes rude to others." (r) & 2.47 & 0.99 & 0.07 & -0.65 & 0.06 & -0.56 & 0.17 & 0.35 \\
\hline $\mathrm{C} 2$ & "has difficulty getting started on tasks." & 2.73 & 0.95 & -0.11 & -0.32 & 0.03 & -0.42 & 0.34 & 0.30 \\
\hline $\mathrm{N} 2$ & "tends to feel depressed, blue." & 2.43 & 0.93 & -0.17 & -0.60 & -0.07 & 0.56 & -0.24 & 0.38 \\
\hline $\mathrm{O} 2$ & "has little interest in abstract ideas." (r) & 2.79 & 0.88 & -0.13 & 0.45 & -0.12 & -0.30 & 0.30 & 0.20 \\
\hline E3 & "is full of energy." & 3.40 & 1.06 & -0.36 & -0.24 & 0.63 & 0.10 & 0.12 & 0.42 \\
\hline A3 & "assumes the best about people. & 3.24 & 0.85 & -0.38 & 0.83 & 0.67 & 0.07 & 0.08 & 0.46 \\
\hline $\mathrm{C} 3$ & "is reliable & 3.13 & 0.94 & -0.36 & 0.05 & 0.59 & 0.03 & -0.04 & 0.34 \\
\hline N3 & "is emotio & 3.47 & 0.96 & -0.15 & 0.00 & -0.49 & 0.24 & 0.23 & 0.35 \\
\hline $\mathrm{O} 3$ & with new ideas & 2.93 & 0.98 & -0.28 & -0.16 & 0.54 & 0.24 & 0.14 & 0.37 \\
\hline E4 & "is outgoing, sociable." & 3.11 & 0.96 & -0.36 & 0.01 & 0.58 & 0.12 & 0.13 & 0.36 \\
\hline A4 & "can be cold and ur & 2.85 & 0.92 & 0.09 & 0.22 & 0.13 & -0.22 & 0.54 & 0.36 \\
\hline $\mathrm{C} 4$ & "keep & 3.39 & 0.80 & 0.05 & 0.67 & 0.50 & -0.13 & -0.35 & 0.38 \\
\hline $\mathrm{N} 4$ & "is relaxec & 3.42 & 0.86 & -0.27 & 0.51 & -0.68 & 0.20 & 0.25 & 0.56 \\
\hline $\mathrm{O} 4$ & "has few artistic & 3.02 & 0.75 & -0.27 & 1.93 & -0.43 & -0.17 & 0.16 & 0.24 \\
\hline E5 & "prefers to have others take charge." (r) & 3.08 & 0.82 & -0.01 & 0.95 & -0.18 & 0.04 & 0.46 & 0.25 \\
\hline A5 & "is respectful, treats others with respect." & 3.58 & 0.92 & -0.31 & 0.11 & 0.61 & -0.30 & -0.15 & 0.48 \\
\hline $\mathrm{C} 5$ & "is persistent, works until the task is finish & 3.57 & 0.97 & -0.20 & -0.15 & 0.62 & -0.32 & -0.26 & 0.55 \\
\hline N5 & "feels secure, comfortable." (r) & 3.34 & 0.87 & -0.25 & 0.69 & -0.67 & 0.11 & 0.14 & 0.48 \\
\hline O5 & "is complex, a deep thinker." & 2.97 & 0.98 & -0.22 & -0.05 & 0.49 & 0.18 & 0.10 & 0.29 \\
\hline E6 & is less active than people. ${ }^{\mathrm{a}}(\mathrm{r})$ & 3.22 & 0.99 & -0.09 & -0.17 & 0.04 & 0.02 & 0.44 & 0.20 \\
\hline A6 & "tends to find fault with others." (r) & 2.89 & 0.77 & -0.44 & 1.45 & -0.12 & -0.31 & 0.38 & 0.26 \\
\hline C6 & "can be somewhat careless." (r) & 2.89 & 0.81 & -0.08 & 0.79 & 0.16 & -0.18 & 0.55 & 0.37 \\
\hline N6 & "is temperamental, gets emotional easily." & 2.50 & 0.90 & -0.33 & -0.56 & 0.00 & 0.55 & -0.07 & 0.31 \\
\hline O6 & "has little creativity." (r) & 3.11 & 0.94 & 0.01 & 0.12 & 0.00 & 0.05 & 0.55 & 0.30 \\
\hline
\end{tabular}

a Original item: "is less active than other people." Note. Items from Soto and John (2017, pp. 79-80); measured on a five-point scale of rating ranging from disagree strongly to agree strongly. $\mathrm{h}^{2}=$ communality. $(\mathrm{r})=$ item is reversely scored. $\mathrm{E}=$ Extraversion, $\mathrm{A}=$ Agreeableness, $\mathrm{C}=$ Conscientiousness, $\mathrm{N}=$ Neuroticism, $\mathrm{O}=$ Openness. Factoring method $=$ WLS. Rotation = varimax. Standardized loadings $>|.3|$ in bold. Overall, $34 \%$ variance extracted: $16 \% \mathrm{~F} 1,10 \% \mathrm{~F} 2,8 \%$ F3.

\section{DISCUSSION AND CONCLUSION}

The perceived personality of Lexi, a type Pepper model, does not seem to follow the Big Five: the corresponding CFA did not converge. The EFA with three factors and varimax rotation yielded a loading matrix where items from all Big Five facets load on the three factors. The first factor (F1) may be labeled as perceived positive characteristics: "is full of energy", "assumes the best about people", "is reliable, can 
always be counted on", "is original, comes up with new ideas", and "is outgoing, sociable" (Soto \& John, 2017 , p. 80). The second factor (F2) could be labeled as negative characteristics: "worries a lot", "is dominant, acts as a leader", "tends to feel depressed, blue", "is temperamental, and "gets emotional easily" (Soto \& John, 2017, pp. 79-80). The third factor (F3) may comprise characteristics hard to assess for the students: "can be cold and uncaring", "can be somewhat careless", and "has little creativity" (Soto \& John, 2017 , pp. 79-80). Only the first factor shows sufficient internal consistency reliability $(\omega>$.7). The construct 'positive characteristics' of the robot may be useful because it is moderately to highly correlated with the intention to use the robot for learning purposes ( $\mathrm{r}_{\text {latent }}=.487, \mathrm{p}<.001$ ). Our results may lend support to Mou et al. (2020) who claim that inventories designed for capturing human personality may not be well suited for social robots. Hence, an undeniable limitation of our study is the use of a Big Five inventory. Conceptual research is necessary to gain a better understanding of the construct 'personality of social robots'. Empirical research should examine this construct much more comprehensively than our study.

\section{REFERENCES}

Belpaeme, T., Kennedy, J., Ramachandran, A., Scassellati, B., \& Tanaka, F. (2018). Social robots for education: A review. Science Robotics, 3(21), 1-9. https://doi.org/10.1126/scirobotics.aat5954

Cooney, M., \& Leister, W. (2019). Using the Engagement Profile to Design an Engaging Robotic Teaching Assistant for Students. Robotics, 8(1), 1-26. https://doi.org/10.3390/robotics8010021

Craenen, B. G.W., Deshmukh, A., Foster, M. E., \& Vinciarelli, A. (2018). Shaping Gestures to Shape Personality: Big-Five Traits, Godspeed Scores and the Similarity-Attraction Effect. In M. Dastani, M. Sukthankar, E. André, \& S. Koenig (Eds.), Proceedings of the 17th International Conference on Autonomous Agents and Multiagent Systems (pp. 2221-2223). Stockholm: International Foundation for Autonomous Agents and Multiagent Systems.

Gardecki, A., \& Podpora, M. (2017). Experience from the operation of the Pepper humanoid robots. Piscataway, NJ: IEEE. https://doi.org/10.1109/PAEE.2017.8008994

Goldberg, L. R. (1990). An alternative "description of personality": The Big-Five factor structure. Journal of Personality and Social Psychology, 59(6), 1216-1229. https://doi.org/10.1037/0022-3514.59.6.1216

Goretzko, D., Pham, T. T. H., \& Bühner, M. (2019). Exploratory factor analysis: Current use, methodological developments and recommendations for good practice. Current Psychology. Advance online publication. https://doi.org/10.1007/s12144-019-00300-2

Guggemos, J., Burkhard, M., Seufert, S., \& Sonderegger, S. (2020). Social Robots as Teaching Assistance System in Higher Education: Conceptual Framework for the Development of Use Cases. Proceedings of the 12th International Conference on Computer Supported Education (CSEDU), 125-132. https://doi.org/10.5220/0009794801250132

Guggemos, J., Seufert, S., \& Sonderegger, S. (2020). Humanoid robots in higher education: Evaluating the acceptance of Pepper in the context of an academic writing course using the UTAUT. British Journal of Educational Technology, 51(5), 1864-1883. https://doi.org/10.1111/bjet.13006

Lee, K. M., Peng, W., Jin, S.-A., \& Yan, C. (2006). Can Robots Manifest Personality?: An Empirical Test of Personality Recognition, Social Responses, and Social Presence in Human-Robot Interaction. Journal of Communication, 56(4), 754-772. https://doi.org/10.1111/j.1460-2466.2006.00318.x

McNeish, D. (2018). Thanks coefficient alpha, we'll take it from here. Psychological Methods, 23(3), 412-433. https://doi.org/10.1037/met0000144

Mou, Y., Shi, C., Shen, T., \& Xu, K. (2020). A Systematic Review of the Personality of Robot: Mapping Its Conceptualization, Operationalization, Contextualization and Effects. International Journal of Human-Computer Interaction, 36(6), 591-605. https://doi.org/10.1080/10447318.2019.1663008

Mubin, O., Stevens, C. J., Shahid, S., Mahmud, A. A., \& Dong, J.-J. (2013). A Review of the applicability of robots in education. Technology for Education and Learning, 1(1), 1-7. https://doi.org/10.2316/Journal.209.2013.1.209-0015

Soto, C. J., \& John, O. P. (2017). Short and extra-short forms of the Big Five Inventory-2: The BFI-2-S and BFI-2-XS. Journal of Research in Personality, 68, 69-81. https://doi.org/10.1016/j.jrp.2017.02.004

Walters, M. L., Syrdal, D. S., Dautenhahn, K., te Boekhorst, R., \& Koay, K. L. (2008). Avoiding the uncanny valley: robot appearance, personality and consistency of behavior in an attention-seeking home scenario for a robot companion. Autonomous Robots, 24(2), 159-178. https://doi.org/10.1007/s10514-007-9058-3

Watkins, M. W. (2018). Exploratory Factor Analysis: A Guide to Best Practice. Journal of Black Psychology, 44(3), 219-246. https://doi.org/10.1177/0095798418771807 